\title{
Microstructure and heat treatment effect on transformation strain in steels: part1 experiment
}

\author{
Takayuki Otsuka (1) ${ }^{a}$, Daisuke Satani ${ }^{\mathrm{a}}$, Kenji Yamamoto ${ }^{\mathrm{b}}$, Kazuo Okamura ${ }^{\circ}{ }^{\mathrm{a}}$, Renald Brenner ${ }^{\mathrm{c}}$ and \\ Brigitte Bacroix (D) \\ ${ }^{a}$ Research \& Development, Nippon Steel and Sumitomo Metal Corporation, Chiba, Japan; ${ }^{b}$ Nippon Steel \& Sumikin Technology, Amagasaki, \\ Japan; 'Institut Jean le Rond d'Alembert, Université Pierre et Marie Curie, Paris, France; ${ }^{\mathrm{d}}$ Laboratoire des Sciences des Procédés et des \\ Matériaux, Université Paris, Villetaneuse, France
}

\begin{abstract}
Anisotropic strain is observed during phase transformation even though no external stress is applied when band structure is formed. The anisotropic strain can result in a change in shape and dimension or residual stress after heat treatment process and thus it achieved much attention. In this paper, three steel grades with different carbon content were prepared to explore the effect of carbon amount and resulting pearlite band thickness as well as heat treatment condition on anisotropic dilatation behaviour during phase transformation. Steel grades containing 0.05 and $0.15 \mathrm{wt}-\%$ carbon exhibit a pronounced anisotropy during reverse transformation, whereas 0.44 wt-\% carbon shows more isotropic transformation strain. During cooling, transformation strain is anisotropic but less pronounced than that during heating.
\end{abstract}

\section{KEYWORDS}

Transformation strain; anisotropic dilatation; band structure

\section{Introduction}

During phase transformation of steels, transformation strain occurs as a consequence of volume change in conjunction with the lattice reconstruction. Transformations from bcc to fcc lattice or vice versa ideally result in an isotropic strain as both lattice structures are cubic. In the real heat treatment process, however, an anisotropic strain during phase transformation is sometimes observed.

One of the agents that causes anisotropic strain is band structure, a laminated microstructure of segregation band. Kop et al. [1] investigated steels with and without band structure revealing anisotropic transformation strain during cooling was found only in the band structured specimen due to the difference of transformation dilatation between layers yielding strain accommodation that is anisotropic. Wei et al. [2] studied the anisotropic transformation strain in forged D2 tool steel. This mechanism was put forward by Jaramillo et al. $[3,4]$ to the cyclic heat treatment and dimensional change in the specimen was found. Another attempt was made on the quenching process of thick plates by Siwecki et al. [5]. It claims that the same mechanism is invoked during quenching resulting in anisotropic transformation expansion behaviour. More recently, anisotropic dilatation during phase transformation was associated with the carbide size and characteristics [6]. Together with the texture effect $[7,8]$, the microstructural directionality is of great interest as it affects the products' shape and dimension as well as the residual stress and eventual mechanical properties [9-12].

These prominent works cover many topics of interest but little have been made on the investigation of effect of chemical composition and heat treatment condition (i.e. heating rate, cooling rate, heating temperature etc.) on the anisotropic transformation strain.

In this study, three types of carbon manganese steels with different carbon contents will be investigated to reveal the effect of chemical composition and heat treatment condition on the anisotropic dilatation during phase transformation.

\section{Experimental conditions}

Three steel grades containing chemical composition shown in Table 1 are cast into $95 \mathrm{~mm}$ thick ingots and then hot rolled to $15 \mathrm{~mm}$. Cylinder shaped specimens having $3 \mathrm{~mm}$ diameter and $10 \mathrm{~mm}$ length for dilatometry tests are taken from the hot rolled sheets whose longitudinal direction is parallel to normal direction (hereafter denoted as 'Normal'), to rolling direction ('Rolling') and to transverse direction ('Transversal'). The specimens have an incomplete hole of $2.6 \mathrm{~mm}$ bore and $4 \mathrm{~mm}$ depth from the bottom surface to allow measuring temperature by welded thermocouples. As the 
Table 1. Chemical composition of three carbon manganese steel grades (wt-\%).

\begin{tabular}{lccccc}
\hline Steel grade & C & Si & Mn & $P$ & S \\
\hline CMn1 & 0.05 & 0.013 & 0.98 & $<0.002$ & 0.0014 \\
CMn2 & 0.15 & 0.016 & 0.98 & $<0.002$ & 0.0016 \\
CMn3 & 0.44 & 0.017 & 0.97 & $<0.002$ & 0.0016 \\
\hline
\end{tabular}

bottom surface of the specimen is fixed, the displacement of the top surface represents the elongation during thermal processing, which is measured by a Magnescale transducer through a rod made from fused quartz. The rod weighs $0.21 \mathrm{~g}$ and thus this does not cause transformation plasticity at any temperature range in this study.

These specimens are heated up to $900^{\circ} \mathrm{C}$ using induction heating. Here, two constant heating rates from ambient temperature to $900^{\circ} \mathrm{C}$ are adopted, namely 1 and $10^{\circ} \mathrm{C} \mathrm{s}^{-1}$. At this temperature, isothermal holding is carried out for $300 \mathrm{~s}$ which is followed by either slow cooling $\left(0.33^{\circ} \mathrm{C} \mathrm{s}^{-1}\right)$ by natural cooling or quenching $\left(40^{\circ} \mathrm{C} \mathrm{s}^{-1}\right)$ by He gas cooling. During the procedure, temperature is controlled under practically no loading condition (as discussed above) when strain derived from thermal and transformation dilation is measured.

\section{Results and discussions}

\section{Microstructure}

Normal, Rolling and Transversal cross sections of hot-rolled sheet samples are etched in nital solution to reveal ferrite boundaries and pearlite fraction; their optical microscopy images are demonstrated in Figure 1.

These figures obviously exhibit pearlite bands which are spreading as thin layers perpendicular to thickness direction. Steel grade CMn2 shows clearer pearlite band than CMn1 reflecting the rich carbon content in CMn2. $0.44 \%$ amount of carbon content in CMn3 results in excessive pearlite formation that yields hardly visible band structure. For CMn1 steel grade, about four ferrite grains can be observed in between two pearlite bands, whereas for CMn2 about two ferrite grains exist in between pearlite bands. For CMn3, ferrite grains are

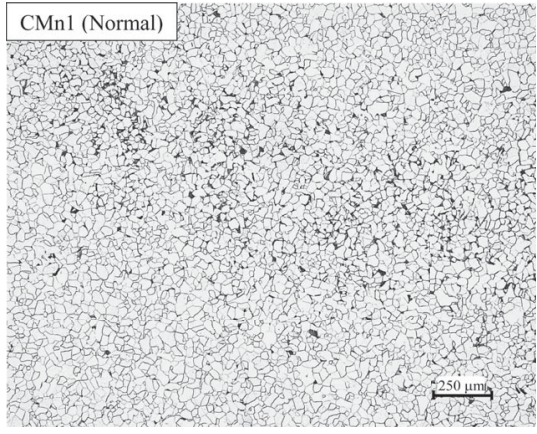

(a)

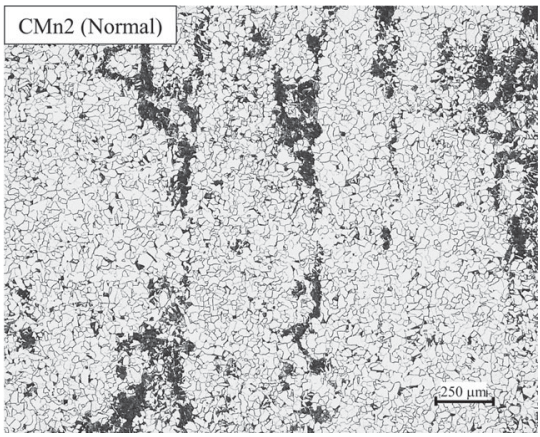

(d)

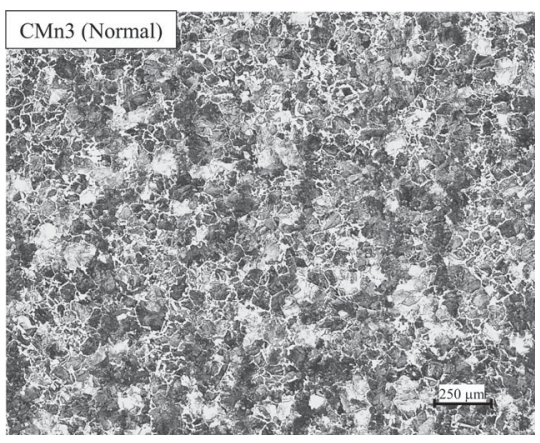

(g)

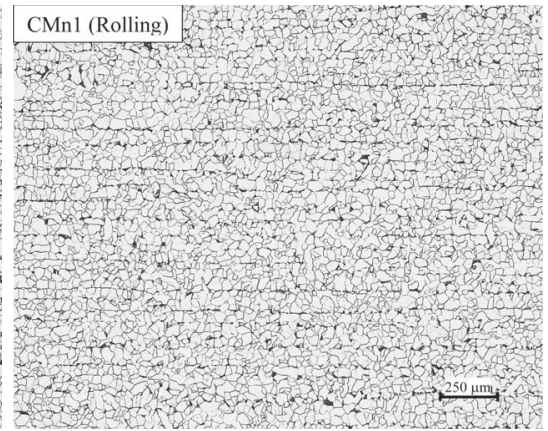

(b)

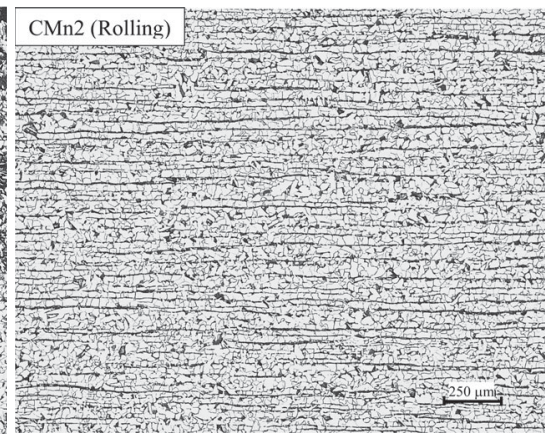

(e)

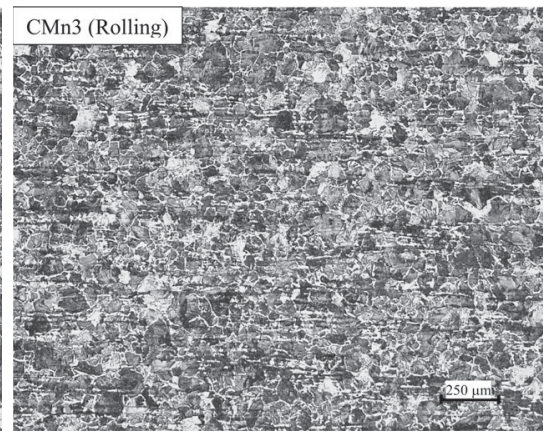

(h)

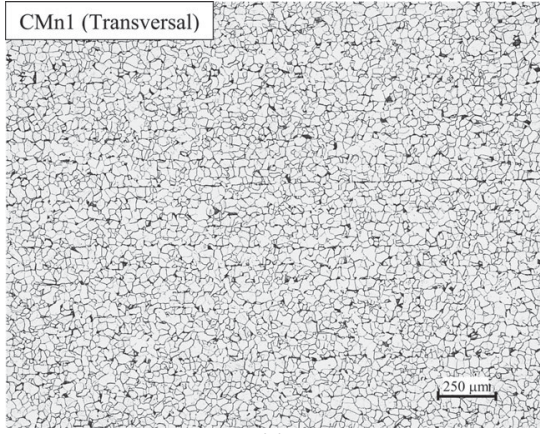

(c)

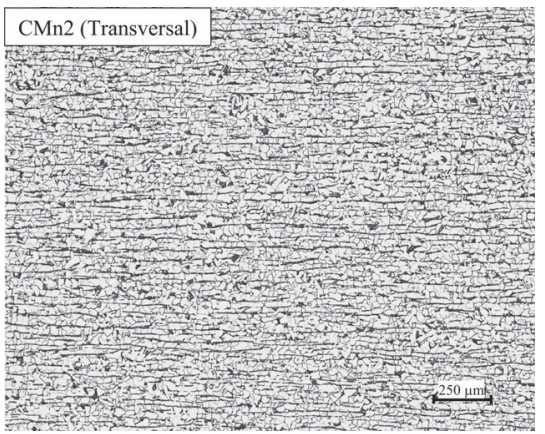

(f)

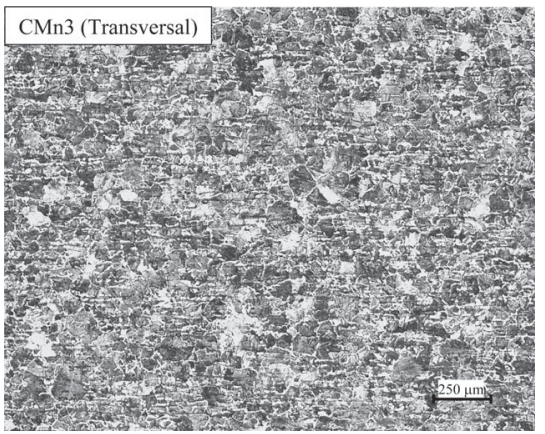

(i)

Figure 1. Optical microscope image of microstructure of each steel grade before heat treatment. 
observed along the prior austenite grain boundary and quite thin ferrite bands can be seen.

\section{Temperature-strain curves}

Strain is calculated by simply divide the elongation by the initial length of the specimen. Strain changes as a result of temperature evolution and phase transformation. Thus, the strain should contain the thermal strain as well as the transformation strain because practically no load is applied during the heat treatment process. Obtained strain results for each steel grade and each direction under the heat treatment condition of heating rate $1^{\circ} \mathrm{C} \mathrm{s}^{-1}$ and cooling rate $0.33^{\circ} \mathrm{C} \mathrm{s}^{-1}$ are depicted in Figure 2.

The Ac1 and Ac3 temperatures for each steel grade are: 710 and $870^{\circ} \mathrm{C}$ for $\mathrm{CMn} 1,715$ and $840^{\circ} \mathrm{C}$ for $\mathrm{CMn} 2$ and 700 and $775^{\circ} \mathrm{C}$ for $\mathrm{CMn} 3$, while the Ar1 and Ar3 temperatures for each steel grade are: 630 and $820^{\circ} \mathrm{C}$ for $\mathrm{CMn} 1,620$ and $760^{\circ} \mathrm{C}$ for $\mathrm{CMn} 2$ and 635 and $715^{\circ} \mathrm{C}$ for $\mathrm{CMn} 3$, respectively. Thus, in this case, the carbon content affect mainly on Ac3 and Ar3 temperatures. It can also be seen that the transformation strain in normal direction decreases significantly during $\alpha \rightarrow \gamma$ phase transformation in CMn1 and CMn2 steel grades. This can be explained by the heterogeneity of phase transformation between ferrite and pearlite bands. The pearlite band initiates austenite phase transformation at relatively lower temperature than ferrite band. In this case, volume shrinkage in pearlite band occurs whereas ferrite volume remains same and this causes the strain incompatibility between ferrite and pearlite bands. In ferrite band, compressive stress in rolling and transversal direction is applied accommodating the volume shrinkage of pearlite band. In contrast, tensile stress in rolling and transversal direction is applied in pearlite band as the ferrite band volume does not change in this stage. During phase transformation, when stress is applied, even if it is lower than yield stress, significant plastic deformation occurs, which is called transformation plasticity [13-16]. Strictly speaking, the phenomenon of the present study is not transformation plasticity as no external stress is applied. However, if we focus on a ferrite or pearlite layer, the anisotropic transformation strain is caused by constraint of other layers and resultant plastic strain. This constraint can be considered as the external stress for the single layer and thus the similar mechanism to transformation plasticity is invoked. To take this effect into consideration, the transforming pearlite band is likely to deform according to the applied stress. This causes the additional tensile strain in the pearlite layer in both rolling and transversal direction resulting in compressive strain in normal direction because of the incompressibility of plastic deformation. By contrast to CMn1 and CMn2, CMn3 steel grade does not exhibit obvious anisotropy during austenite phase transformation. This is because the

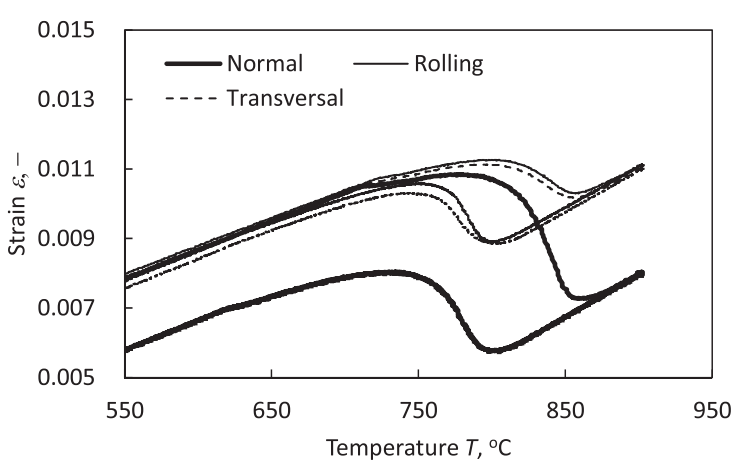

(a) CMn1 - Heating rate $=1{ }^{\circ} \mathrm{C} / \mathrm{s}$, Cooling rate $=0.33{ }^{\circ} \mathrm{C} / \mathrm{s}$

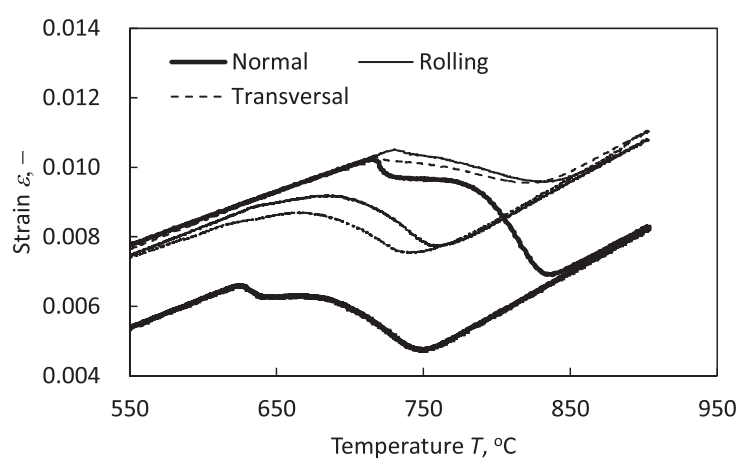

(b) $\mathrm{CMn} 2$ - Heating rate $=1{ }^{\circ} \mathrm{C} / \mathrm{s}$, Cooling rate $=0.33{ }^{\circ} \mathrm{C} / \mathrm{s}$

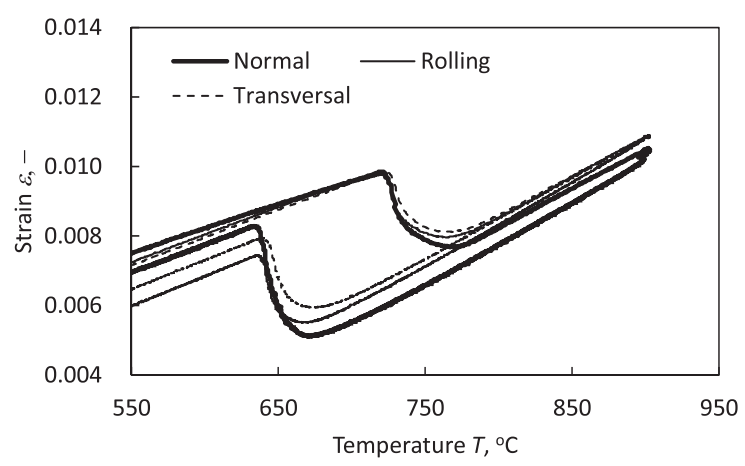

(c) CMn3 - Heating rate $=1{ }^{\circ} \mathrm{C} / \mathrm{s}$, Cooling rate $=0.33{ }^{\circ} \mathrm{C} / \mathrm{s}$

Figure 2. Temperature strain curves of each steel grade during heat treating. (case of heating rate $=1{ }^{\circ} \mathrm{Cs}^{-1}$ and cooling rate $=0.33^{\circ} \mathrm{Cs}^{-1}$ )

initial microstructure is more homogeneous than those of CMn1 and CMn2 and the plastic deformation caused by pearlite decomposition is randomly occurred.

For a quantitative investigation of anisotropic dilatation during phase transformation, thermal strain is removed from the total strain during heating and cooling. Thermal strain can be calculated by an extrapolation of austenite or ferrite/pearlite curves. Then, volume fraction of daughter phase and transformation strain can be estimated using lever rule. Here, we define a total transformation strain as a strain difference between $\gamma$ and $\alpha$ phases at 50\% transformed temperature under a given heating/cooling condition 
(transformation strain is a dependent on temperature as the linear thermal expansion coefficients of $\gamma$ and $\alpha$ phases are different). With this method, evolution of transformation strain of CMn1 during heating at the heating rate of $1^{\circ} \mathrm{C} \mathrm{s}^{-1}$ is depicted in Figure 3(a).

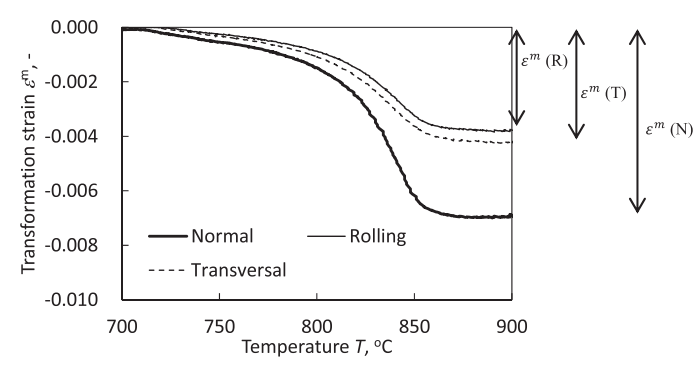

(a) $\mathrm{CMn} 1-$ Heating rate $=1{ }^{\circ} \mathrm{C} / \mathrm{s}$

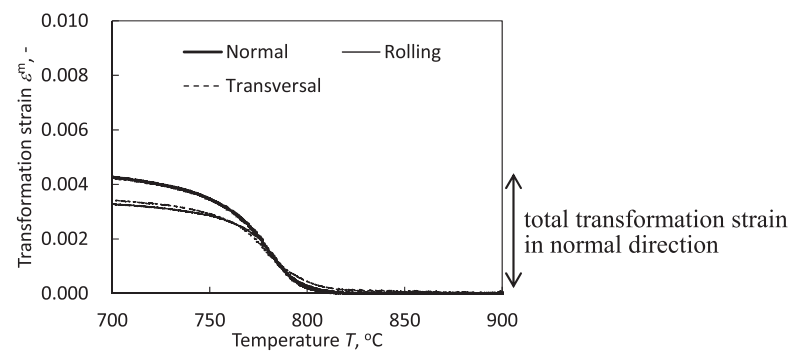

(b) $\mathrm{CMn} 1-$ Cooling rate $=0.33^{\circ} \mathrm{C} / \mathrm{s}$

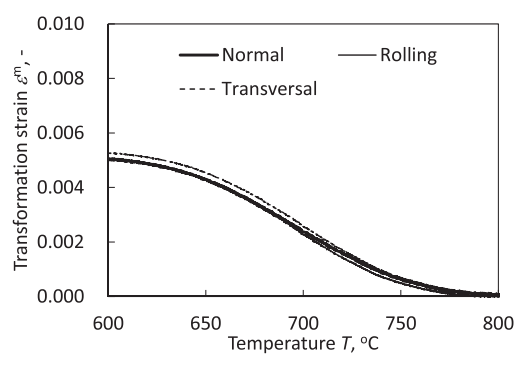

(c) $\mathrm{CMn} 1-$ Cooling rate $=40^{\circ} \mathrm{C} / \mathrm{s}$

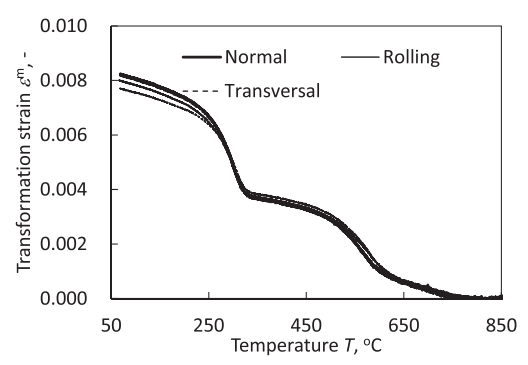

(d) $\mathrm{CMn} 3-$ Cooling rate $=40^{\circ} \mathrm{C} / \mathrm{s}$

Figure 3. Comparison of transformation strain for each direction during cooling.
While, transformation strains of CMn1 during cooling at the cooling rates of 0.33 and $40^{\circ} \mathrm{Cs}^{-1}$ are shown in Figure 3(b,c), respectively. For CMn3, transformation strain during cooling at the cooling rate of $40^{\circ} \mathrm{C} \mathrm{s}^{-1}$ is shown in Figure 3(d). Anisotropic transformation strain is more apparent by extracting thermal strain as demonstrated in Figure 3. An apparent anisotropy is found in CMn1 when transformation taking place during heating. An anisotropic transformation strain also manifests during phase transformation under $0.33^{\circ} \mathrm{C} \mathrm{s}^{-1}$ cooling rate in CMn1 - Figure $3(\mathrm{~b})$. This result agrees qualitatively with the previous works [1]. This is to be contrasted to the behaviour if the cooling rate is $40^{\circ} \mathrm{Cs}^{-1}$, an isotropic transformation strain is found under high cooling rate. This may be caused by relatively homogeneous phase transformation achieved by high cooling rate because diffusion of alloying elements during phase transformation is more restricted. Indeed, the transformation strain in CMn3 under $40^{\circ} \mathrm{C} \mathrm{s}^{-1}$ cooling rate is also confirmed to be isotropic even though partially martensite phase transformation occurs. This implies that the anisotropy effect during cooling should be determined according to the heating temperature and holding time as higher temperature and more holding time result in homogenisation of alloying elements.

A comprehensive result of total transformation strain for each sense is summarised in Table 2 for heating and in Table 3 for cooling as well as in Figure 4 (for Table 3 and Figure 4, the initial heating rate is $1^{\circ} \mathrm{C} \mathrm{s}^{-1}$ for all cooling conditions).

The previous consequences can be also drawn from these results; CMn1 and CMn2 exhibit most pronounced anisotropic transformation strain during heating while CMn3 shows isotropic.

Table 3. Anisotropic total transformation at 50\% transformed temperature strain observed during $\gamma \rightarrow \alpha$ phase transformation.

\begin{tabular}{|c|c|c|c|c|c|c|}
\hline \multirow{4}{*}{$\begin{array}{l}\text { Steel } \\
\text { grade }\end{array}$} & \multicolumn{6}{|c|}{ Transformation type: $\gamma \rightarrow \alpha$} \\
\hline & \multicolumn{6}{|c|}{ Heating rate $=1{ }^{\circ} \mathrm{Cs}^{-1}$} \\
\hline & \multicolumn{3}{|c|}{ Cooling rate $=0.33^{\circ} \mathrm{Cs}^{-1}$} & \multicolumn{3}{|c|}{ Cooling rate $=40^{\circ} \mathrm{C} \mathrm{s}^{-1}$} \\
\hline & Normal & Rolling & Transversal & Normal & Rolling & Transversal \\
\hline CMn1 & 0.00458 & 0.00345 & 0.00357 & 0.00515 & 0.00514 & 0.00536 \\
\hline CMn2 & 0.00440 & 0.00360 & 0.00366 & 0.00510 & 0.00493 & 0.00503 \\
\hline CMn3 & 0.00368 & 0.00305 & 0.00305 & 0.00824 & 0.00800 & 0.00770 \\
\hline
\end{tabular}

Table 2. Anisotropic total transformation strain at 50\% transformed temperature observed during $\alpha \rightarrow \gamma$ phase transformation.

\begin{tabular}{|c|c|c|c|c|c|c|}
\hline \multirow[b]{3}{*}{ Steel grade } & \multicolumn{6}{|c|}{ Transformation type: $\alpha \rightarrow \gamma$} \\
\hline & \multicolumn{3}{|c|}{ Heating rate $=1^{\circ} \mathrm{Cs}^{-1}$} & \multicolumn{3}{|c|}{ Heating rate $=10^{\circ} \mathrm{Cs}^{-1}$} \\
\hline & Normal & Rolling & Transversal & Normal & Rolling & Transversal \\
\hline CMn1 & -0.00697 & -0.00381 & -0.00426 & -0.00646 & -0.00356 & -0.00386 \\
\hline CMn2 & -0.00577 & -0.00356 & -0.00431 & -0.00671 & -0.00342 & -0.00309 \\
\hline CMn3 & -0.00329 & -0.00372 & -0.00380 & -0.00449 & -0.00378 & -0.00389 \\
\hline
\end{tabular}




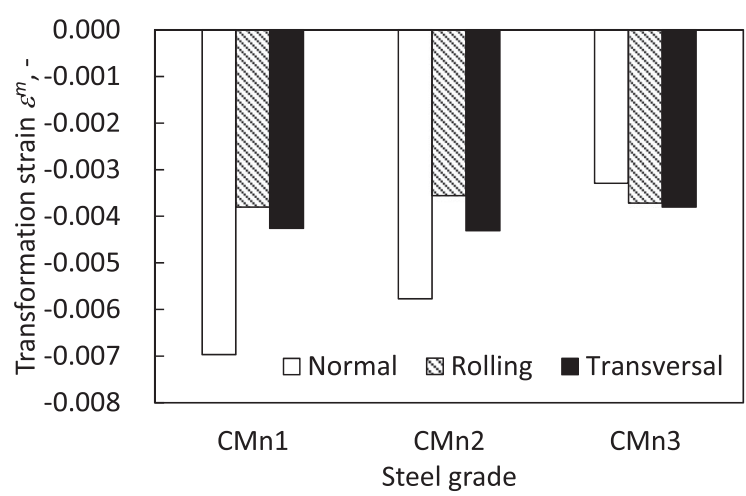

(a) Heating (heating rate $=1{ }^{\circ} \mathrm{C} / \mathrm{s}$ )

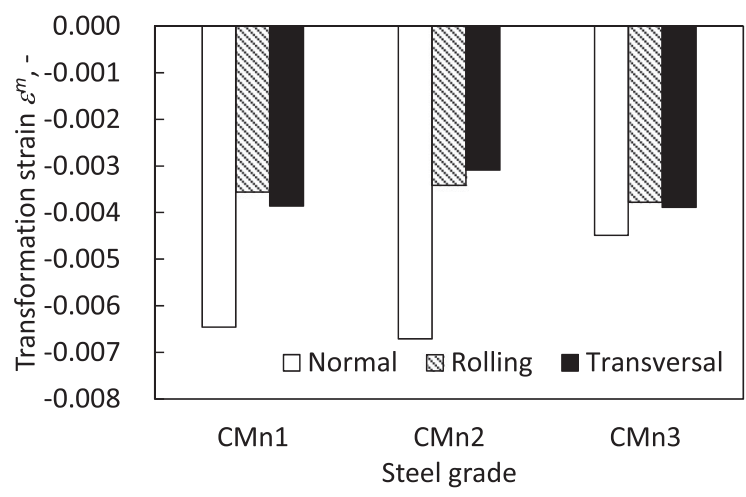

(b) Heating (heating rate $=10{ }^{\circ} \mathrm{C} / \mathrm{s}$ )

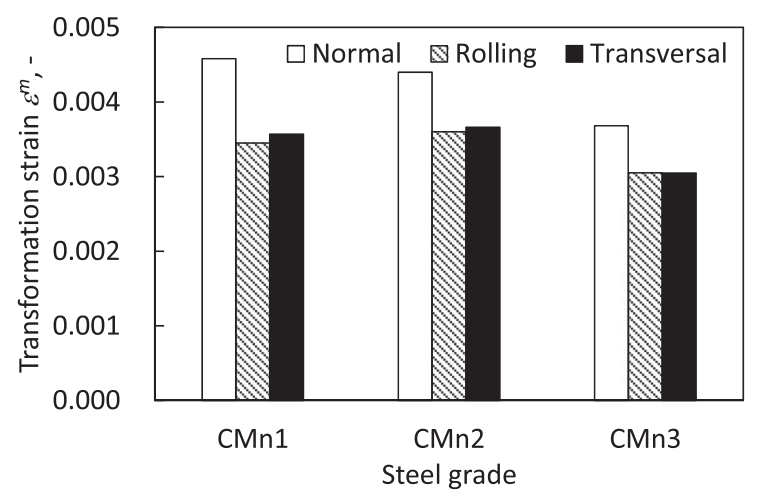

(c) Cooling (heating rate $=1{ }^{\circ} \mathrm{C} / \mathrm{s}$, cooling rate $=0.33{ }^{\circ} \mathrm{C} / \mathrm{s}$ )

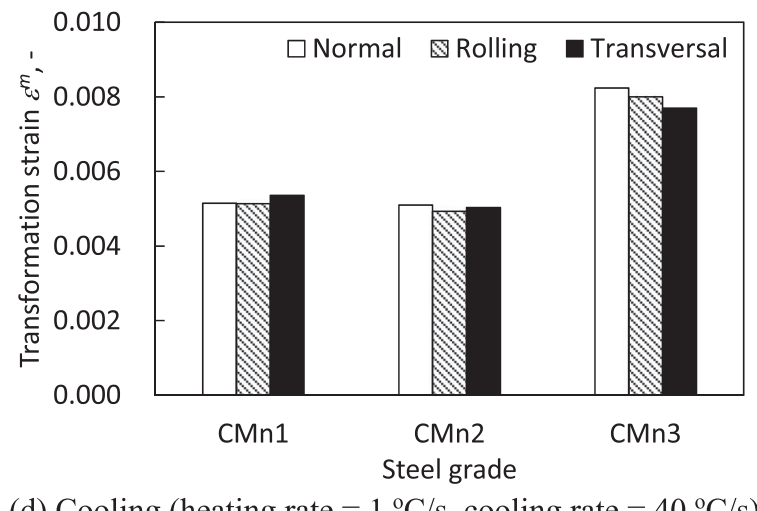

(d) Cooling (heating rate $=1{ }^{\circ} \mathrm{C} / \mathrm{s}$, cooling rate $=40^{\circ} \mathrm{C} / \mathrm{s}$ )

Figure 4. Comparison of transformation strain for each direction during heating $(a, b)$ and cooling $(c, d)$.

In contrast to the results by heating shown in Table 2 and Figure $4(\mathrm{a}, \mathrm{b})$, anisotropy by cooling does not manifest an apparent effect of chemical composition as indicated in Table 3 and Figure 4(c,d). The steel grade $\mathrm{CMn} 3$ shows larger transformation volume expansion during cooling at the cooling rate of $40^{\circ} \mathrm{C} \mathrm{s}^{-1}$ than that of $0.33^{\circ} \mathrm{C} \mathrm{s}^{-1}$. This indicates the formation of the martensite phase which can be also deduced from Figure 3.

As $\mathrm{CMn} 2$ has an equivalent carbon and manganese contents with those found in the previous work [1], anisotropy during slow cooling is now compared quantitatively. In this reference, total transformation strain in normal direction was 0.0050 and in longitudinal (rolling) direction was 0.0029 , whereas the values are found to be, respectively, 0.0044 and 0.0036 in this study. Thus a slight weak anisotropy is found in this study. The transformation temperature for both cases is similar but the distance between pearlite bands is reported about $20 \mu \mathrm{m}$ in reference while about $25 \mu \mathrm{m}$ in this study. This difference may be attributed to the cooling rate during casting that imposes segregation and rolling reduction ratio which decides distance between pearlite bands. The fact infers that the anisotropic behaviour, especially one takes a quantitative approach, is a complicated nature which is not identical even though similar chemical composition and similar heat treatment is adopted.

\section{Conclusion}

Three carbon manganese steel grades having different carbon content have been employed to identify the effect of carbon content (CMn1:0.05, CMn2:0.15, CMn3:0.44wt-\%) on anisotropic dilatation during phase transformation. The pearlite band structure is found in CMn1 and CMn2 which results in a significant anisotropy in transformation strain during phase transformation. Increase of carbon content as well as acceleration of cooling rate $\left(0.33^{\circ} \mathrm{C} \mathrm{s}^{-1}\right.$ to $40^{\circ} \mathrm{C} \mathrm{s}^{-1}$ for $\gamma \rightarrow \alpha$ phase transformation) can reduce anisotropy effect due to more homogeneous phase transformation which is assumed to attributes the transformation timing between band structures.

\section{Disclosure statement}

No potential conflict of interest was reported by the authors.

\section{ORCID}

Takayuki Otsuka (D) http://orcid.org/0000-0003-4326-7357 Kazuo Okamura (D) http://orcid.org/0000-0001-5356-1619 Brigitte Bacroix (iD) http://orcid.org/0000-0001-6138-9935

\section{References}

[1] Kop TA, Sietsma J, Van der Zwaag S. Anisotropic dilatation behaviour during transformation of hot rolled steels showing banded structure. Mater Sci Technol. 2001;17:1569-1574. 
[2] Wei J, Kessler O, Hunkel M, et al. Anisotropic phase transformation strain in forged D2 tool steel. Mater Sci Technol. 2004;20:909-914.

[3] Jaramillo RA, Lusk MT, Mataya M C. Dimensional anisotropy during phase transformations in a chemically banded 5140 steel. Part I: experimental investigation. Acta Mater. 2004;52:851-858.

[4] Jaramillo RA, Lusk MT. Dimensional anisotropy during phase transformations in a chemically banded 5140 steel. Part II: modelling. Acta Mater. 2004;52:859-867.

[5] Siwecki T, Koziel T, Hutchinson B, et al. Effect of microsegregation on phase transformation and residual stress. Mater Sci Forum. 2007; 539-543:4596-4601.

[6] Hong K-J, Song J-H, Park S-H, et al. Improvement of anisotropic distortion of SKD11 tool steel during heat treatment. Proceedings of the 17th International Federation for Heat Treatment and Surface Engineering Congress; 2008.

[7] Hutchinson B. Critical assessment 16: anisotropy in metals. Mater Sci Technol. 2015;31:1393-1401.

[8] Wilson DV. Origins of directional mechanical properties. Met Technol. 1975;2(1):8-20.

[9] Morrison WB. Influence of testing direction on the mechanical properties of wrought steel. Met Technol. 1975;2(1):33-41.
[10] Forsyth PJE, Stubbington CA. Directionality in structureproperty relationships: aluminium and titanium alloys. Met. Technol. 1975;2(1):158-177.

[11] Maina E, Crowther DN, Banerjee JR, et al. Influence of directionality on strength and impact behaviour of high strength steels. Mater Sci Technol. 2011;28(4):390-396.

[12] Scott R. Directionality of mechanical properties in hotrolled steel plates. Met Technol. 1976;3(1):71-78.

[13] Greenwood GW, Johnson RH. The deformation of metals under small stresses during phase transformations. Proc R Soc. 1965;283A:403-422.

[14] Inoue T, Wang ZG, Miyao K. Simulation of quenching process of carburized steel gear wheel under metallothermo-mechanical CouplingElsevier science publishers, Paris, B. V. North-Holland. Proceedings of IUTAM Thermomechanical Coupling Solids; 1987-1985. p. 257-262.

[15] Otsuka T, Wakasu Y, Inoue T. A simple identification of transformation plastic behaviour and some data for heat treating materials. Int J Mater Prod Technol. 2005;24(1-4):292-305.

[16] Otsuka T, Akashi T, Ogawa S, et al. Effect of volume expansion on transformation plasticity during ferrite and martensite transformation of steel. J Soc Mater Sci JPN. 2011;60(10):937-942. 